\title{
RANCANG BANGUN ROBOT KRI 2012
}

\author{
Andreas Hadi ${ }^{1)}$, Agus Halim ${ }^{2)}$ dan Noor Eddy ${ }^{3)}$ \\ 1) Jurusan Teknik Mesin Universitas Tarumanagara, Jakarta \\ ${ }^{2)}$ Praktisi Industri Otomasi, P.T. Matahari Megah Tangerang \\ 3) Jurusan Teknik Mesin Universitas Trisakti, Jakarta \\ e-mail: agushalim@mm.co.id
}

\begin{abstract}
Designing Robot KRI 2012 is applied in the industrial world that serves as a means of shifting materials. At KRI 2012 the game that took the motto "Peng on Dai Gat" and the theme "In Pursuit of Peace and Prosperity". Robot designed KRI 2012 which is the type of manual robot that has some tasks that take up, lift, and insert tokens into the token box, lift the basket, also the collector robot design will discuss base design such as determined DC motors, lifting, minimum pressure on the gripper token, the determine of PWM DC motor, slope and deflection that occurs on the rod lifter. So in designing this robot should also be able to support the weight of the operator who will be driving this robot. The method used is to use a simple calculation of the literature used to obtain data on the results of the design and use test with tachometer to get the motor and calculate the mileage time of the robot at $6 \mathrm{~m}$. Then the data will be used as input to obtain design models robot KRI 2012 on Autodesk Inventor 2012.
\end{abstract}

Keywords : KRI 2012, base design, PWM, Autodesk Inventor 2012

\section{PENDAHULUAN}

Pada perkembangan teknologi dunia modern ini sangat membantu kinerja manusia dalam kehidupan sehari-hari. Salah satu perkembangan teknologi yang membantu manusia dalam kehidupan sehari-hari adalah teknologi robot. Terdapat beberapa pengertian robot umum digunakan sebagai dasar perancangan:

- Robot merupakan mekanisme instrumental yang digunakan dalam ilmu pengetahuan atau industri untuk menggantikan kerja manusia secara fisik atau tidak menyerupai manusia [2].

- Robot merupakan sebuah perangkat mekanik yang dapat diprogram untuk melakukan beberapa tugas manipulasi atau penggerak dalam kendali otomatis [3].

- Robot adalah sebuah manipulator yang dapat di program ulang untuk memindahkan tool, material, atau peralatan tertentu dengan berbagai program pergerakan untuk berbagai tugas dan juga mengendalikan serta mensinkronkan peralatan dengan pekerjaannya [4].

Secara rutin, Direktorat Jendral Pendidikan Tinggi, DIKTI menyelenggarakan kontes robot yang melibatkan berbagai universitas di Indonesia, termasuk Universitas Tarumanagara. Pada tahun 2012, salah satu skim kontes yang diikuti oleh tim robot Universitas Tarumanagara adalah KRI (Kontes Robot Indonesia). Teknologi robot pada KRI 2012, robot tersebut harus memiliki sistem yang digunakan untuk mengambil token yang berbentuk seperti koin kedalam token box serta harus memindahkan basket. Perancangan sistem mekanis dan elektris dilakukan untuk memenuhi kriteria yang ditetapkan penyelenggara lomba, yang merupakan tujuan dari perancangan ini. Semua hal tersebut merupakan aplikasi-aplikasi pada ruang lingkup teknik mesin, industri, serta otomasi secara khusus yang berfungsi alat pemindah bahan. Peralatan pemindah bahan dgunakan untuk memindahkan muatan dilokasi atau area, departemen, pabrik, lokasi konstruksi, tempat penyimpanan, dan pembongkaran muatan [1].

Aplikasi-aplikasi tersebut antara lain tampak dari komponen-komponen yang dirancang dan digunakan pada robot KRI 2012, antara lain: mencengkaram token, yang digunakan untuk memindahkan token dari dan ke tempat yang telah ditentukan, perancangan batang pengangkat, pemilihan kapasitas motor penggerak, serta pemilihan PWM motor DC. Karena KRI 2012 dioperasikan oleh operator dengan cara mengendarainya, maka kekuatan struktur dan rangka dasar dari KRI 2012 dirancang dengan baik. 


\section{METODE PERANCANGAN}

Perancangan robot KRI 2012 dilakukan dengan studi literatur dan studi lapangan untuk mendapatkan kriteria perancangan yang tepat. Pemodelan geomteri dilakukan untuk mendapatkan gambar kerja robot yang sesuai. Analisis struktur dilakukan dengan metode Finite Element Analysis yang terdapat pada perangkat lunak Autodeks Inventor 2012. Perancangan pada sistem penggerak dilakukan dengan menggunakan tachometer untuk mengetahui putaran yang dihaslkan motor. Gambar 1 merepresentasikan proses perancangan terhadap KRI 2012.

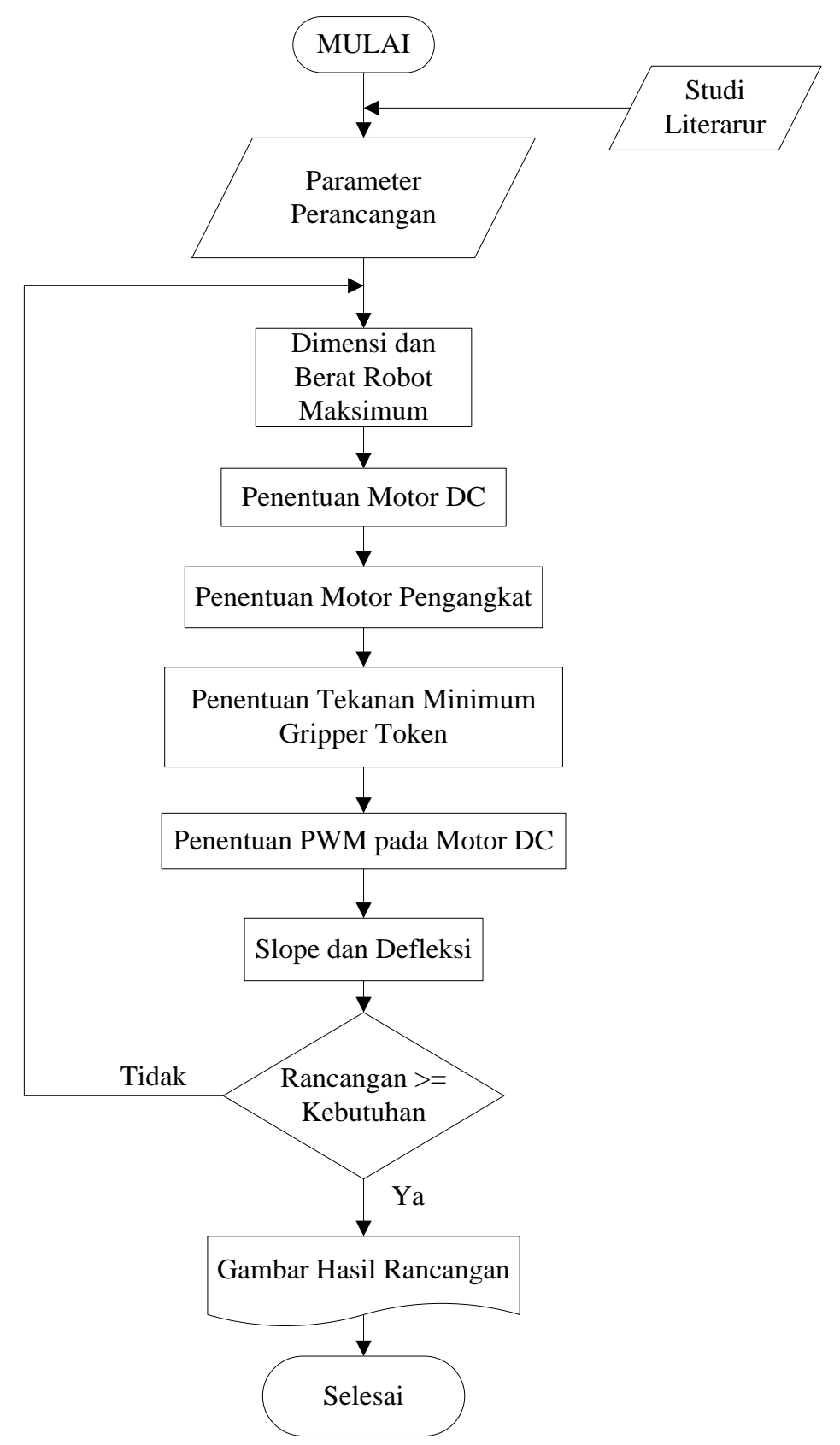

Gambar 1. Diagram alir perancangan

\section{Motor DC}

Motor DC merupakan jenis motor yang menggunakan tegangan searah sebagai sumber tenaganya. Dengan memberikan beda tegangan pada kedua terminal tersebut, motor akan berputar pada satu arah, dan bila polaritas dari tegangan tersebut dibalik maka arah putaran motor akan terbalik pula. Motor DC banyak digunakan untuk menggerakkan robot dikarenakan diperlukan torsi yang tinggi atau percepatan yang tetap. 
Kecepatan motor bergerak:

$$
v=\omega R
$$

Dengan:

$$
\begin{array}{ll}
v & : \text { Kecepatan robot }[\mathrm{m} / \mathrm{s}] \\
\omega & : \text { Kecepatan sudut }[\mathrm{rad} / \mathrm{s}] \\
R & : \text { Jari-jari roda }[\mathrm{m}]
\end{array}
$$

Motor DC dan penggerak dihungkan dengan menggunakan transmisi rantai, dengan rasio kecepatan VR;

$$
\mathrm{VR}=\frac{N_{1}}{N_{2}}: \frac{T_{2}}{T_{1}}
$$

Keterangan:

VR : Velocity ratio

$\mathrm{N}_{1}$ : Kecepatan putaran sprocket kecil [1/min]

$\mathrm{N}_{2}$ : Kecepatan putaran sprocket besar [1/min]

$\mathrm{T}_{1}$ : Jumlah gigi pada sprocket kecil

$\mathrm{T}_{2}$ : Jumlah gigi pada sprocket besar

\section{Mekanisme Pengangkat}

Mekanisme pengangkat pada robot manual KRI 2012 ini menggunakan sistem katrol. Beban maksimun tali yang terjadi

dengan:

$$
S=\frac{\pi d^{2}}{4} \sigma_{t p}
$$

$d$ : diameter keliling dari untai [cm]

$S$ : beban pada tali [kg]

Torsi yang diperlukan oleh motor pengangkat beban untuk mengangkat beban yaitu:

$$
\tau=F . r
$$

dengan:

$\tau:$ torsi $[\mathrm{Nm}]$

$F$ : gaya total pengangkatan [N]

$r$ : radius motor [m]

\section{Momen Inersia}

Momen inersia berarti ukuran kelebaman suatu benda untuk berotasi terhadap porosnya. Momen inersia berarti besaran yang nilainya tetap pada suatu gerak rotasi. Besaran ini analog dengan massa pada gerak translasi atau lurus.

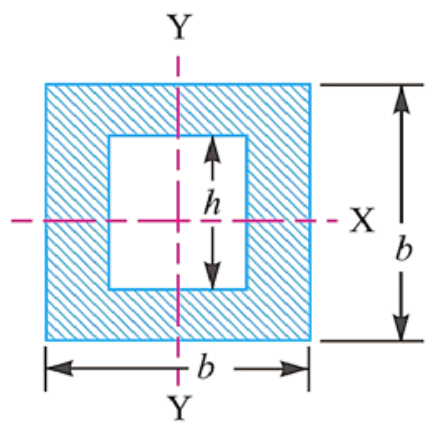

Gambar 2. Momen inersia pada Hollow Square [5]

Rangka KRI 2012 menggunakan rangka jenis hollow square, dengan momen inersia: 
dengan:

$$
I_{x x}: I_{y y}=\frac{\left(b^{4}-h^{4}\right)}{12}
$$

I : momen inersia

$b$ : exterior side

$h$ : interior side

\section{Momen Bending}

Rangka dasar (base plate) memegang peranan yang sangat penting karena merupakan tempat komponen dan beban-beban lain bertumpu [6]. Oleh karena itu akan terjadi defleksi yang umumnya tidak sama disetiap bagian, yang juga menyebabkan slope yang disetiap bagiannya juga tidak sama. Dalam perancangan base plate ini terjadi defleksi pada batang tumpuan sederhana dengan beban terdistribusi merata.

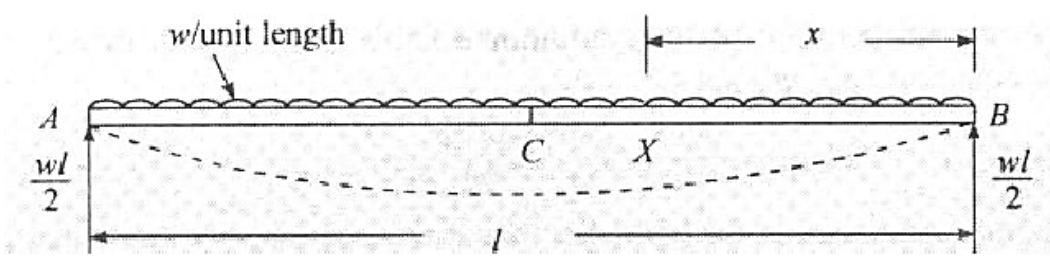

Gambar 3. Defleksi batang tumpuan sederhana dengan distribusi merata [7]

Defleksi maksimum yang terjadi dapat dirumuskan dengan persamaan berikut:

$$
\delta_{\max }=\frac{w \cdot l^{4}}{8 E I}
$$

Dengan:

$$
\begin{array}{lll}
\delta_{\max } & \text { defleksi maksimun [m] } \\
w & : & \text { momen gaya [Nm] } \\
l & : & \text { panjang batang [m] } \\
E & : & \text { modulus elastisitas [GPa] } \\
I & : & \text { momen inersia [mm } \left.{ }^{4}\right]
\end{array}
$$

Slope yang terjadi dapat dirumuskan sebagai berikut

$$
\theta=\frac{w \cdot l^{3}}{6 E I}
$$

Dengan:

$$
\begin{array}{lll}
\theta & : & \text { slope }\left[{ }^{\circ}\right] \\
w & : & \text { momen gaya }[\mathrm{Nm}] \\
l & : & \text { panjang batang }[\mathrm{m}] \\
E & : & \text { modulus elastisitas [GPa] } \\
I & : & \text { momen inersia }\left[\mathrm{mm}^{4}\right]
\end{array}
$$

\section{HASIL DAN PEMBAHASAN}

Berdasarkan perhitungan dari robot KRI 2012 didapatkan torsi yang dibutuhkan oleh robot KRI 2012 untuk motor DC sebesar 43,232 Nm serta motor pengangkat 0,53 Nm. Kecepatan pergerakkan robot KRI sebesar $5,167 \mathrm{~m} / \mathrm{s}^{2}$ dengan rasio kecepatan sebesar 5,45 . Tali pengangkat yang digunakan tali kermantel dengan diameter $3 \mathrm{~mm}$ yang mampu menahan erat sebesar 14,83 kg. Tekanan minimum pada gripper token sebesar 0,2 MPa untuk mencegah terjatuhnya token yang memiliki gaya berat sebesar $11,87 \mathrm{~N}$. Pada batang pengangkat terjadi defleksi sebesar 9,38 x $10^{-4}$ $\mathrm{m}$, slope $1.25 \times 10^{-3}$ derajat, serta momen inersia 4904,08 $\mathrm{mm}^{4}$.

Berdasarkan hasil pengujian didapatkan data-data uji PWM terhadap putaran motor DC serta waktu tempuh pada Tabel 1: 
Tabel 1. Data uji PWM terhadap putaran motor DC (1/min)

\begin{tabular}{ccc}
\hline No & PWM $(\%)$ & $1 / \mathrm{min}$ \\
\hline 1 & 10 & $166,5 \pm 1,546$ \\
2 & 20 & $343,9 \pm 1,145$ \\
3 & 30 & $364,4 \pm 1,364$ \\
4 & 40 & $405,5 \pm 1,055$ \\
5 & 50 & $428,8 \pm 0,935$ \\
6 & 60 & $442,8 \pm 1,676$ \\
7 & 70 & $450,8 \pm 1,625$ \\
8 & 80 & $455,9 \pm 1,588$ \\
9 & 90 & $470,7 \pm 1,587$ \\
10 & 100 & $483,7 \pm 1,561$ \\
\hline
\end{tabular}

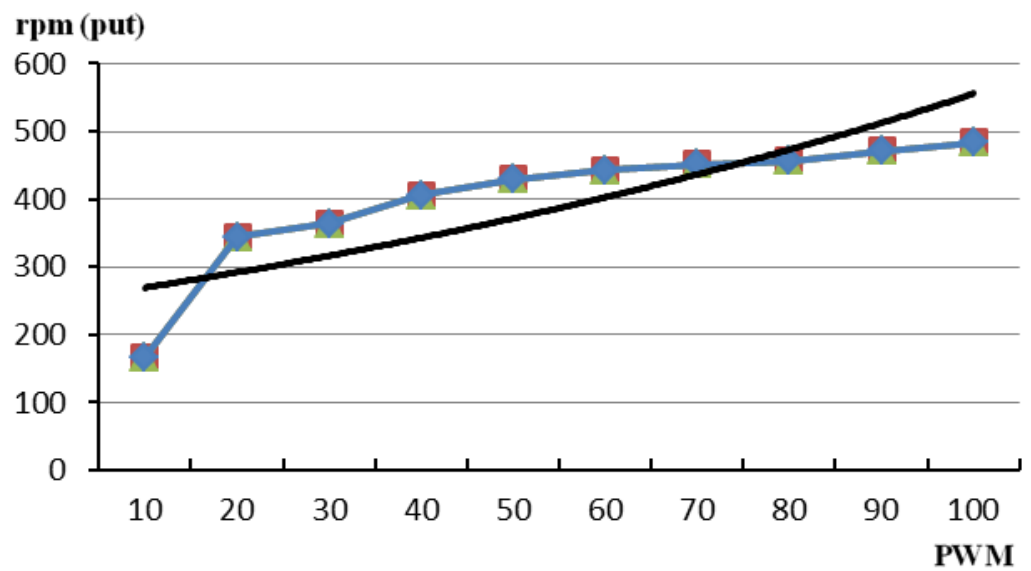

Gambar 4. Grafik hubungan kecepatan putaran motor terhadap PWM

Gambar 4 menunjukkan hubungan antara kecepatan motor DC terhadap PWM. Semakin besar nilai PWM maka akan semakin besar pula kecepatan putaran motor DC. Hal ini disebabkan oleh diaturnya presentase lebar pulsa terhadap perioda dari suatu sinyal dalam bentuk tegangan periodik yang diberikan ke motor sebagai sumber daya. Semakin besar perbandingan lama sinyal dengan perioda sinyal maka akan semakin cepat motor berputar.

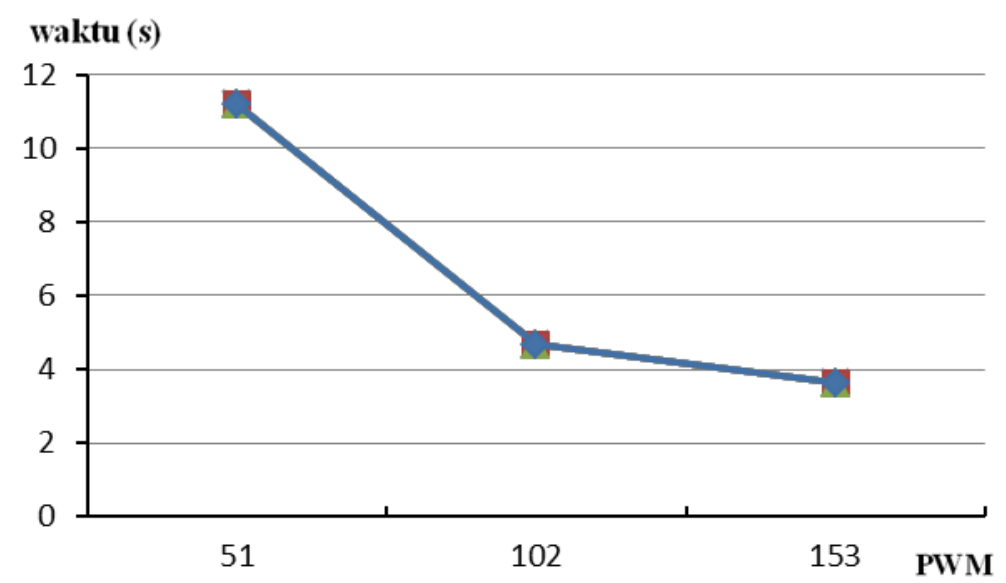

Gambar 5. Data uji PWM terhadap waktu tempuh

Gambar 5 menunjukkan bahwa semakin besar nilai PWM maka akan semakin cepat pula waktu yang ditempuh oleh Robot KRI 2012 ini pada jarak 6 m. Hal ini disebabkan oleh diaturnya 
besaran PWM yang mengakibat kecepatan motor DC yang akan menyebabkan lamanya waktu tempuh robot KRI tersebut.

Tabel 2. Data uji PWM terhadap waktu tempuh

\begin{tabular}{ccc}
\hline No & PWM & Waktu (s) \\
\hline 1 & 51 & 11,18 \\
2 & 102 & 4,68 \\
3 & 153 & 3,62 \\
\hline
\end{tabular}

\section{KESIMPULAN}

Nilai torsi yang dibutuhkan oleh motor penggerak pada KRI 2012 sebesar 43,232 Nm dan 0,53 Nm untuk motor pengangkat. Tali kermantel dengan diameter $3 \mathrm{~mm}$ dapat menahan beban robot collector yang memiliki massa sebesar $7 \mathrm{~kg}$.

Kenaikan putaran motor akan cenderung linier pada PWM lebih dari 20. Nilai PWM berbanding terbalik terhadap waktu tempuh. Hal ini disebabkan kurangnya torsi pada motor DC yang diakibatkan oleh nilai PWM yang kecil akan mengakibatkan putaran motor yang terjadi menjadi kecil.

\section{DAFTAR PUSTAKA}

[1] N. Rudenko. Material Handling Equipment, Second Edition, Moscow: Peace Publisher Moscow, 1964

[3] Encyclopedia Britannica

[4] "A Glossary of Terms fo Robotic" prepared for the Air Force Material Labotary, Wright Pattersin AFB, by the (U.S.) National Bureau of Standards.

[5] Robot Institute of America. United State of America

[6] Khurmi R.S. dan Gupta J.K. A Textbook Of Machine Design. New Delhi : Eurasia Publishing House (PVT.) LTD. 2005

[7] Eddy. Noor dan Winata. Oke, Analis Struktur Chasis Kendaraan Serbaguna untuk Perkebunan, Prosiding Seminar Nasional Mesin dan Industri, 8 Oktober 2009, Jakarta: Universitas Tarumanagara,2009

[8] Diktat Mekanika Kekuatan Material. Tersedia di http://www.scribd.com/doc/90596191/32/ Kantilever-Terbebani-Sebagian-Dengan-Beban-Ter-distribusi-Merata. (17 September 2012) 